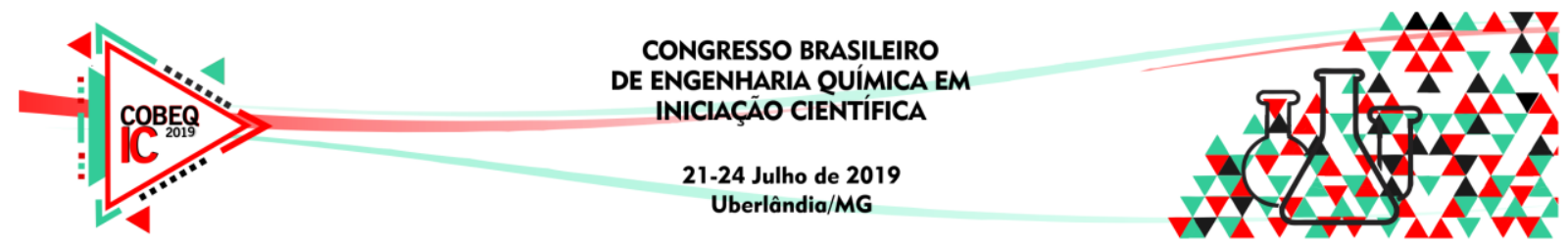

\title{
Secagem solar do fruto cubiu (Solanum sessiliflorum Dunal)
}

\author{
M. P. S. SOUSA ${ }^{1}$, V. A. BEZERRA ${ }^{1}$, I. H. GONÇALVES ${ }^{1}$, L. A. CAVALCANTE ${ }^{2}$ e Y. K. \\ P. GURGEL AUM ${ }^{1}$ \\ ${ }^{1}$ Universidade Federal do Amazonas, Departamento de Engenharia Química \\ ${ }^{2}$ Instituto Federal de Educação, Ciência e Tecnologia do Amazonas, Departamento de \\ Química, Ambiente e Alimentos \\ E-mail para contato: mayrasousa123@hotmail.com
}

\begin{abstract}
RESUMO - Cubiu (Solanum sessiliflorum Dunal) é um fruto nativo da Amazônia. O fruto é rico em minerais, aminoácidos, ácido cítrico, tem baixo teor de gordura e alto teor de umidade. Cubiu é uma fonte significativa de compostos bioativos, como clorofilas, flavonóides e carotenóides. Portanto, é importante analisar o processo de secagem do cubiu como método de preservação de frutos. No presente estudo, o comportamento de secagem de cubiu em um secador solar direto foi estudado. $\mathrm{O}$ experimento de secagem foi realizado com fatias de $4 \mathrm{~mm}$ e alcançou a umidade de equilíbrio em $5 \mathrm{~h}$ de secagem. Os dados de secagem foram ajustados a cinco modelos matemáticos diferentes. A qualidade do ajuste dos modelos propostos foi avaliada por meio da determinação do coeficiente $\left(\mathrm{R}^{2}\right)$ e da raíz quadrada do erro médio (RMSE). Entre os modelos, Page foi o melhor para descrever o comportamento de secagem em camada fina de fatias de cubiu $\left(\mathrm{R}^{2}>0,99\right.$, RMSE < 0,036). O objetivo deste trabalho é propor recomendações para um amplo uso de secadores solares e estudar a viabilidade e a exploração desses sistemas limpos, especialmente na região amazônica.
\end{abstract}

\section{INTRODUÇÃO}

O cubiu (Solanum sessiliflorum Dunal) é um fruto nativo da região amazônica pertencente à família Solanaceae, que nasce de uma planta arbustiva, é também conhecido como Cocona, ou maná-cubiu, ou tomate de índio. É usado regionalmente para a produção de sucos, sorvetes, geleias e também na culinária. Pode também ser empregado na área medicinal para controlar o açúcar no sangue e colesterol (SILVA et al., 1995). É um fruto, em geral, pouco consumido pela população brasileira e é considerado uma planta alimentícia não convencional, esse fator pode ser causado pela sua pequena produção nacionalmente (SERENO et al., 2017).

A maioria dos derivados do maná-cubiu são produzidos por pequenos produtores utilizando o material vegetal para consumo in natura. O cubiu é um fruto que possui um alto teor de umidade, podendo variar entre $88,4 \%$ e 92,1\% (YUYUMA, 2007). Essa característica, o torna propenso a proliferação de microorganismo e a altas atividades enzimática causando oxidação. Para extender o tempo de uso dessas matérias-primas orgânicas são usadas técnicas de processamento com intuito de conservar o alimento para facilitar futuras produções ou transporte, como por exemplo a refrigeração. A secagem é um dos métodos, mais usados para esse propósito, por ser simples e de baixo custo, podendo proteger a matéria agrícola contra deteriorização oxidativa e enzimática (SILVA, 2015). 


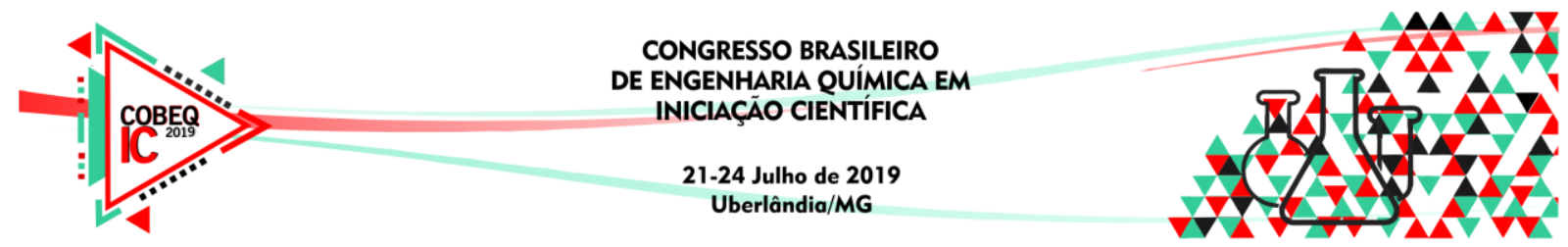

A operação de secagem pode ser analisada a partir da cinética de secagem que determina a rapidez da perda de umidade do sólido. O processo acaba quando a umidade de equilíbrio é atingida. Existem diversos métodos de secagem ou desidratação como: convecção, solar (direto, indireto ou misto) ou mesmo pela estufa. Atualmente, o uso de energia solar tem grande potencial e pode ser empregada em diversas áreas de setores industriais, o processo de desidratação solar, ocorre com auxílio de um secador solar que funciona a partir da convecção natural, sendo ainda exposto diretamente a radiação solar para ser desidratado (CHAUHAN; KUMAR; TEKASAKUL, 2015; RODRIGUEZ, 2018).

O secador, também chamado coletor solar, é um equipamento que possui um funcionamento simples para aquecimento de ar e de baixo custo, tornando-se uma ótima alternativa para regiões de clima tropical. O secador é composto por uma cabine com tampo de vidro com uma inclinação que proporciona uma maior proteção durante o processo para o fruto a ser secado, a massa de ar é aquecida nesse coletor, onde ao atravessar o equipamento sua densidade diminui passando pelo material, e por fim é resfriado por convecção que é causada pela entrada de um ar frio (CELESTINO, 2010).

\section{METODOLOGIA}

A fim de explicar inicialmente os processos necessários para o experimento de secagem foi construído o fluxograma da Figura 1.

Figura 1 - Fluxograma da metodologia.

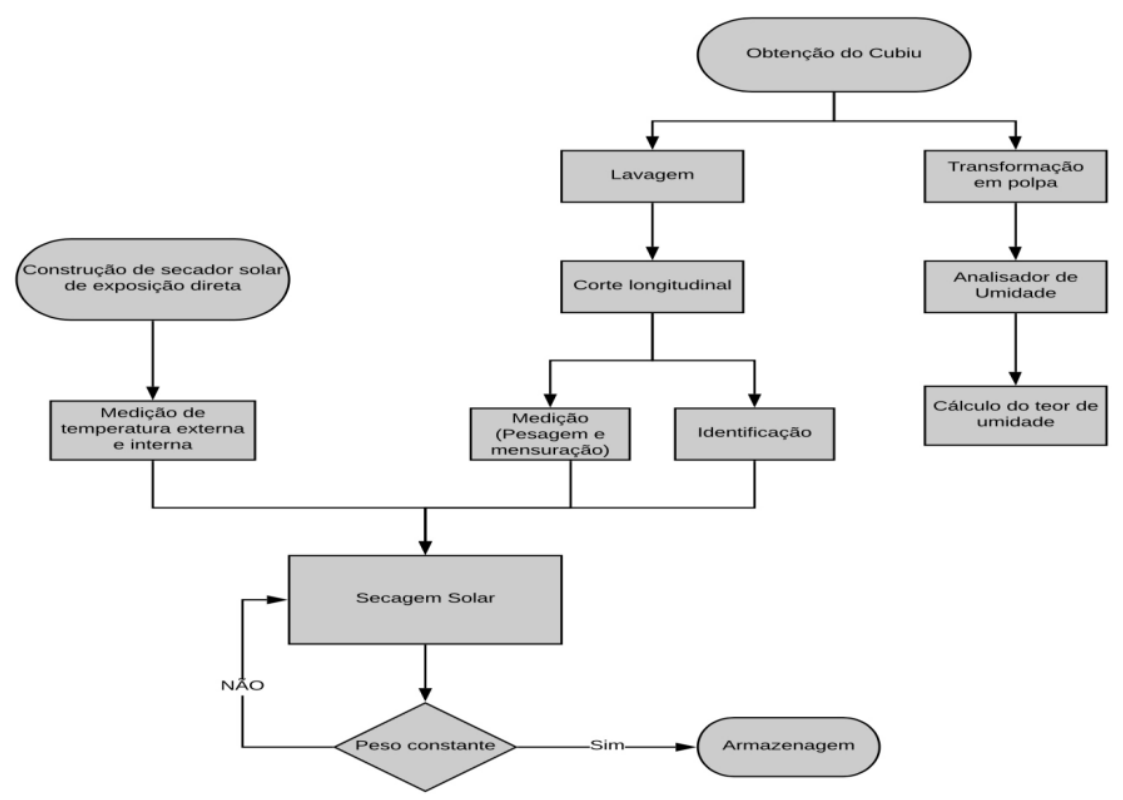

Os frutos de cubiu foram adquiridos na feira SEPROR em Manaus/AM, em julho de 2016. Como mostrado na Figura 1, os frutos foram lavados em água corrente e posteriormente secos em temperatura ambiente, para então serem fatiados longitudinalmente. Uma amostra do fruto foi utilizada para a determinação da umidade inicial, o qual foi triturado para a transformação em polpa que foi, então, submetido à determinação de umidade por infravermelho à temperatura de $105^{\circ} \mathrm{C}$ em triplicata, com o auxílio do analisador de umidade padrão. Os ensaios de secagem foram realizados com fatias de cubiu de $4 \mathrm{~mm}$ de espessura, as quais foram medidas através de um paquímetro, com graduação 0,02 $\mathrm{mm}$. Em seguida foram 


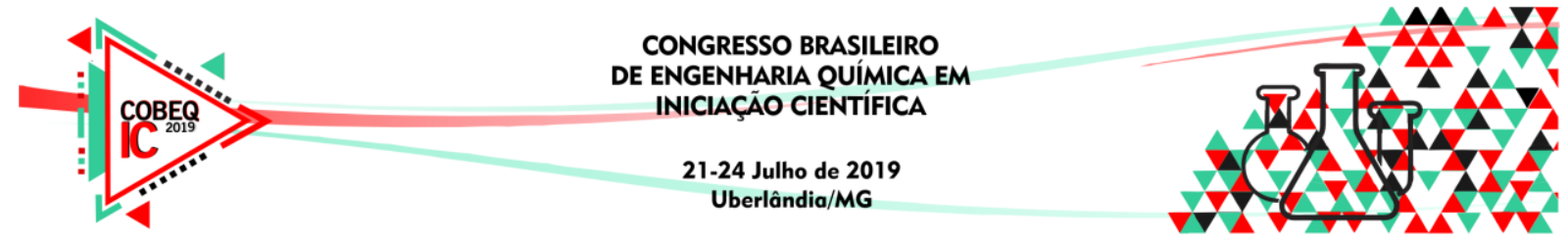

pesadas em uma balança analítica e por fim foram identificadas. Após a pesagem e identificação, as fatias foram colocadas dentro do coletor solar construído como uma câmara de madeira mista com $60 \mathrm{~cm}$ x $60 \mathrm{~cm}$ que possui $20 \mathrm{~cm}$ de altura, com 11 orifícios abertos para passagem do fluxo de ar com diâmetro de $2,5 \mathrm{~cm}$, estando de um lado a $5 \mathrm{~cm}$ de altura e do outro a $12 \mathrm{~cm}$ de altura, mostrado na Figura 2.

Figura 2 - Coletor solar: (a) câmara de madeira com os orifícios para passagem de ar; (b) coletor solar finalizado; (c) fatias no coletor durante a secagem.

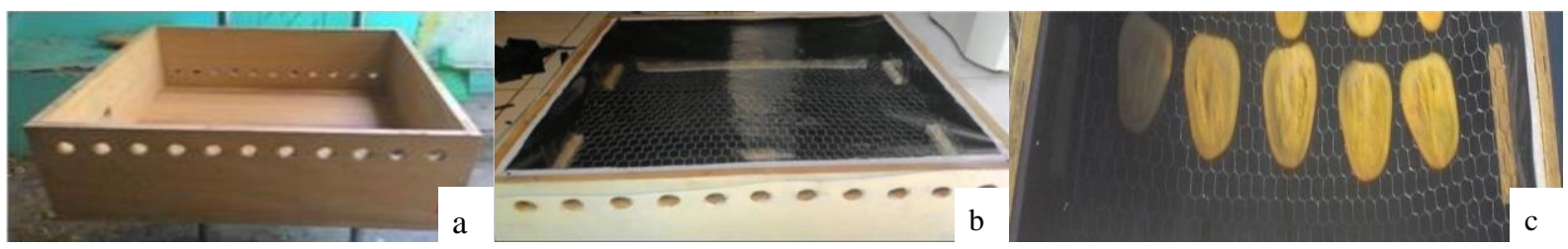

Neste equipamento, ocorreu o processo de secagem, onde os frutos foram submetidos à radiação solar direta, além de correntes de ar introduzidas de forma natural com auxílio dos ventos através de orifícios laterais, essas correntes eram, então, aquecidas pelo efeito estufa dentro do secador. Devido ao gradiente de temperatura do processo de aquecimento, ocorreram transferências de energia entre o meio e as amostras dentro do secador. Ao longo do processo, as fatias foram retiradas para serem pesadas, primeiramente, a cada 30 minutos e, após duas horas, retiravam-se a cada uma hora até se obter massas constantes para cada fatia. $\mathrm{O}$ experimento de secagem foi realizado usando fatias de $4 \mathrm{~mm}$ que foram submetidas ao processo de $9 \mathrm{~h}$ da manhã às $17 \mathrm{~h}$ da tarde, total de $8 \mathrm{~h}$.

A partir dos dados obtidos foi possível calcular a razão de umidade $M R$ utilizando a equação (1).

$M R=\frac{(\mathrm{X}-\mathrm{Xe})}{(\mathrm{Xo}-\mathrm{Xe})}$

Em que: $X$ é a umidade absoluta em base seca; $X e$ é a umidade de equilíbrio em base seca; $X o$ é a umidade inicial em base seca.

Para a elaboração das curvas de secagem foram calculadas as razões de umidade. Modelos matemáticos, mostrados na Tabela 1, foram ajustados aos dados com o intuito de analisar o modelo capaz de descrever o comportamento da curva da operação de secagem do cubiu.

Tabela 1 - Equações dos modelos matemáticos utilizados

\begin{tabular}{ll}
\hline Equação & Referência \\
\hline MR $=\exp (-k . t)$ & Newton (LEWIS, 1921) \\
$M R=\exp \left(-k \cdot t^{n}\right)$ & Page (PAGE, 1949) \\
MR $=$ a.exp $(-k . t)$ & Henderson e Pabis (HENDERSON \& PABIS, 1961) \\
MR $=$ a.exp(-k.t) + c & Logarítmico (YAGCIOGLU et al., 1999) \\
MR $=$ a.exp(-ko.t) + b.exp(-k1.t) & Dois Termos (HENDERSON, 1974) \\
\hline
\end{tabular}




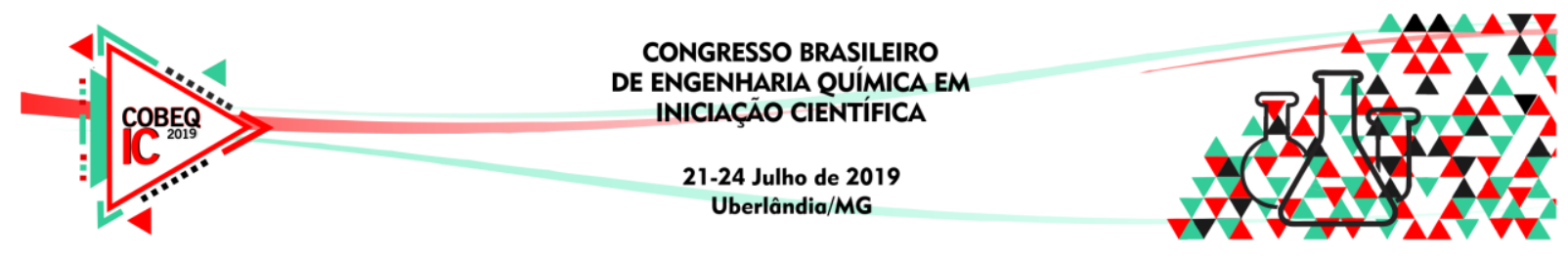

\section{RESULTADOS}

O experimento foi realizado no dia 14 de julho de 2016 e o teor de umidade inicial obtido, a partir de uma amostra original foi de 90,68\% que representa o valor médio das unidades obtidas para cada dia.

Durante o experimento foi aferido a umidade, a temperatura interna e externa do secador com o auxílio de um termo-higrômetro, visando calcular a razão de umidade (MR) a partir da equação (1), a Figura 3 representa a variação da temperatura durante o dia 14/jul, nesta etapa o clima foi predominantemente ensolarado e observa-se que pela manhã a temperatura interna se manteve próximo a $70^{\circ} \mathrm{C}$ e foi gradativamnete diminuindo por volta das 14:00 horas.

Notou-se que a temperatura do ar no interior do equipamento em relação ao fluxo de ar fornecido pelo ambiente, sofreu um aumento gradativo causado pela transferência de calor por convecção, proporcionada pela absorção de energia térmica por radiação solar. Esse processo foi ainda mais efetivo, pois o secador solar é revestido com paredes de coloração escura, aumentando o potencial de absorção de calor que gerou o aquecimento das correntes de vento que transitavam pelo equipamento. Somado a isso, observou-se que o secador manteve uma média de tempetura externa de $34,77{ }^{\circ} \mathrm{C}$, não apresentando demasiada variação ao longo do tempo mesmo estando em contato com as condições ambientais externas.

Figura 3 - Variação da temperatura interna e externa com o tempo para o dia 14.

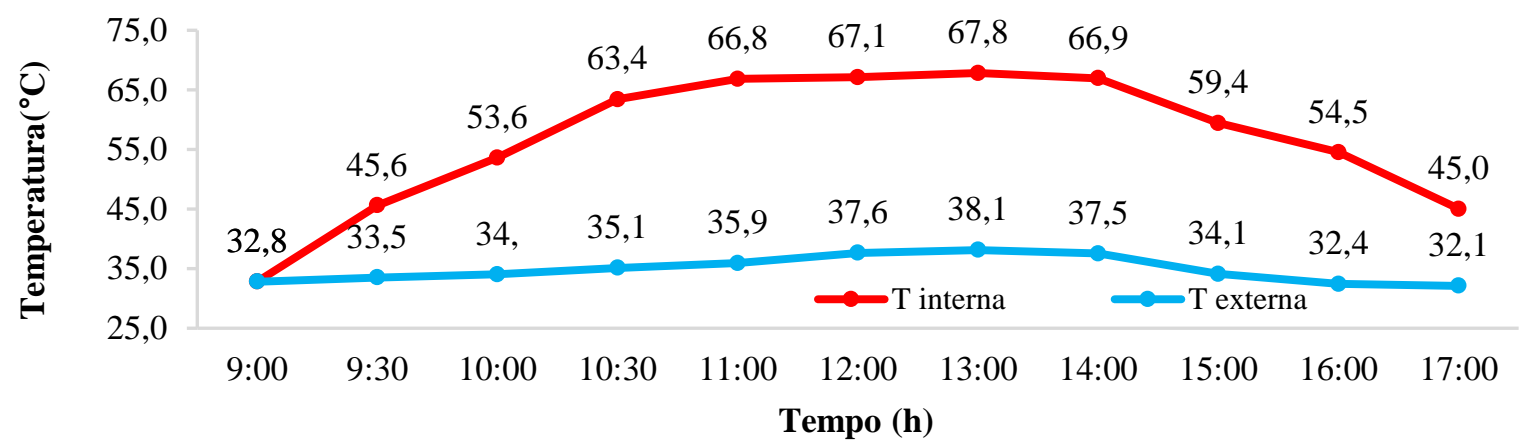

Em outro dia (18 de julho de 2016) referente a Figura 4, foram feitas medições da temperatura interna e externa do coletor para analisar a variação da temperatura local, obsevouse que não ocorreu uma elevada variação de temperatura externa, enquanto a temperatura interna sofreu um elevado aumento nas 2 primeiras horas, ás 13:00 se manteve proximo de 70 ${ }^{\circ} \mathrm{C}$ e em seguida sofreu um resfriamneto gradual até às 17:00.

Figura 4 - Variação da temperatura interna e externa com o tempo para o dia 18.

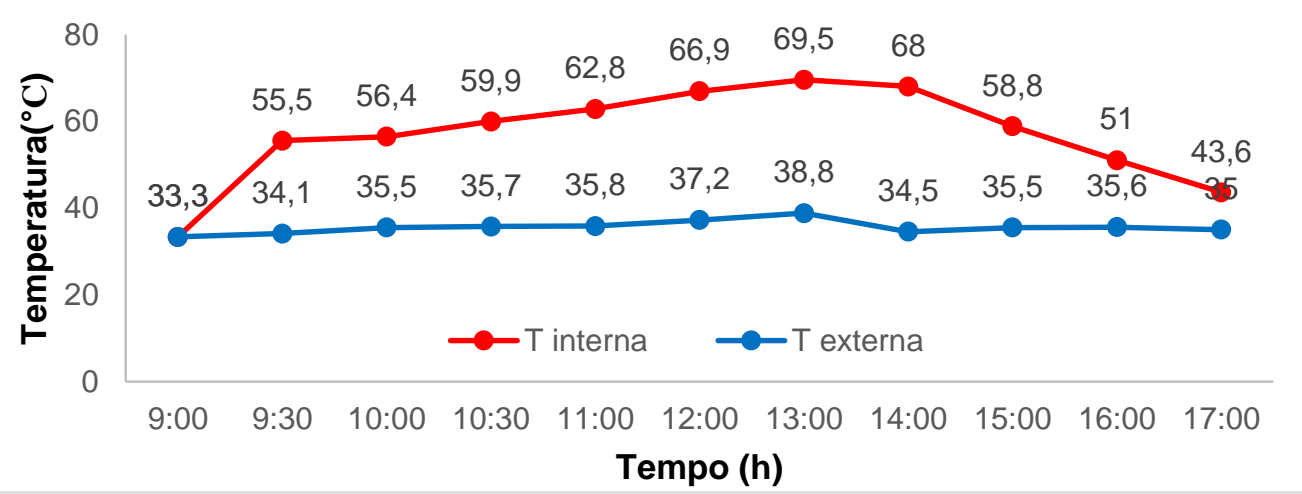




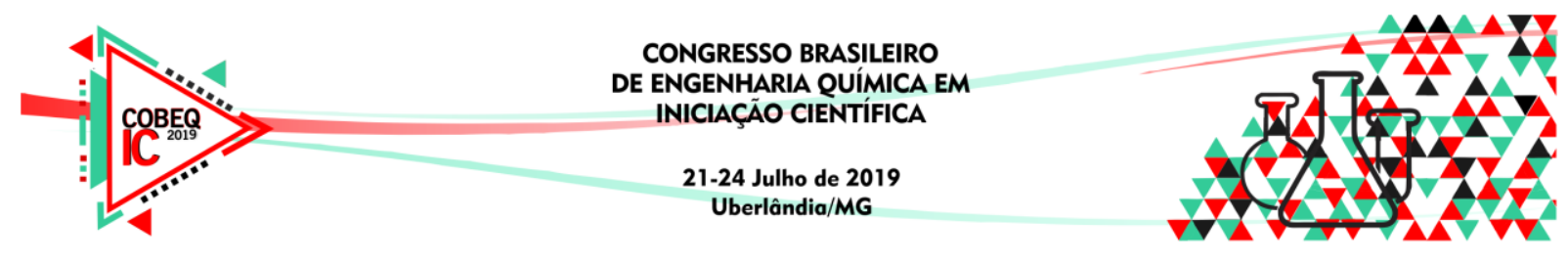

A Figura 5 mostra a curva de cinética de secagem que relaciona as razões de umidade adimensional com o decorrer do tempo para amostras de cubiu de $4 \mathrm{~mm}$ no dia 14/jul. Verificou-se que a cinética é mais acentuada nas 2 primeiras horas com altos valores de MR, devido principalmente à elevada umidade do fruto, enquanto ao atingir $5 \mathrm{~h}$ de secagem sofreu uma diminuição, em razão da obtenção da umidade de equilíbrio, aproximando a razão de umidade à zero demonstrando que de fato, a secagem no cubiu ocorreu de forma eficaz. Notouse que foi atingida massa constante por volta do intervalo de 15:00 à 16:00, e ao fim da secagem, o fruto sofreu um encolhimento, escurecimento e aumento da rigidez devido à retirada de umidade.

Figura 5 - Cinética de secagem das fatias de $4 \mathrm{~mm}$.

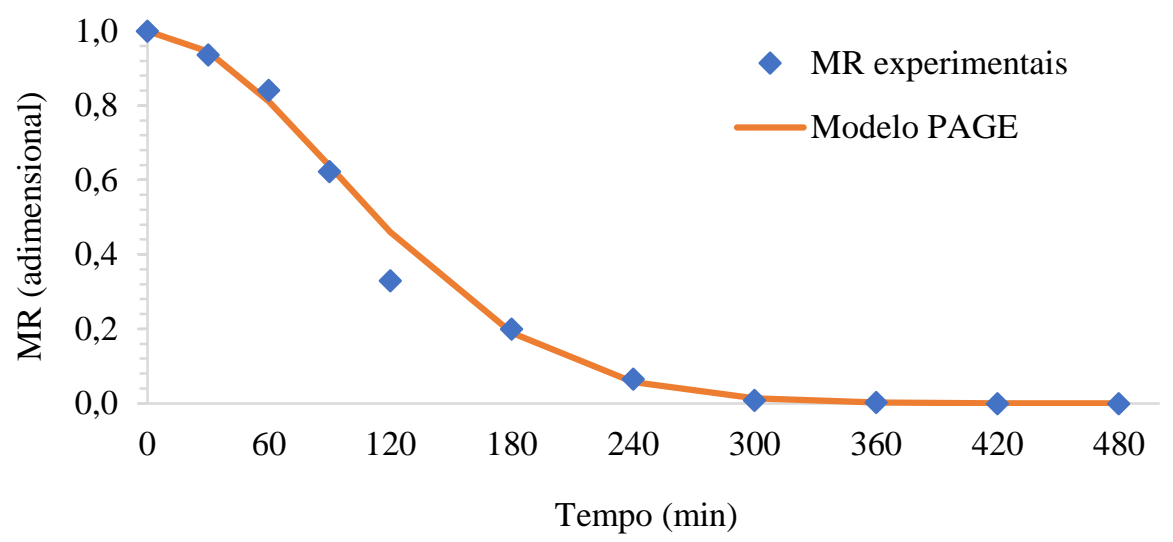

Cinco tipos diferentes modelos matemáticos foram analisados, dentre eles o modelo que obteve os melhores resultados foi o modelo de Page, pois, de acordo com a Tabela 2, apresentou o maior valor $\mathrm{R}^{2}(0,9979)$ e o menor valor de RMSE $(0,035112)$, portanto, esse modelo foi utilizado como referência para modelar a cinética de secagem do cubiu.

Tabela 2- Parâmetros dos modelos matemáticos utilizados.

\begin{tabular}{cccc}
\hline Modelo & Parâmetros & $\boldsymbol{R}^{2}$ & RMSE \\
\hline Newton & $\mathrm{k}=0,4225$ & 0,9826 & 0,103575 \\
Page & $\mathrm{n}=1,8815 ; \mathrm{k}=0,210395$ & 0,9979 & 0,035112 \\
Henderson \& Pabis & $\mathrm{a}=1,1351 ; \mathrm{k}=0,4797$ & 0,9874 & 0,088512 \\
Logaritmo & $\mathrm{a}=1,2274 ; \mathrm{c}=-0,1170 ; \mathrm{k}=0,3796$ & 0,9906 & 0,076494 \\
Dois termos & $\mathrm{a}=0,5675 ; \mathrm{b}=0,5675 ; \mathrm{k} 0=0,4797 ; \mathrm{k} 1=0,4797$ & 0,9874 & 0,088512 \\
\hline
\end{tabular}




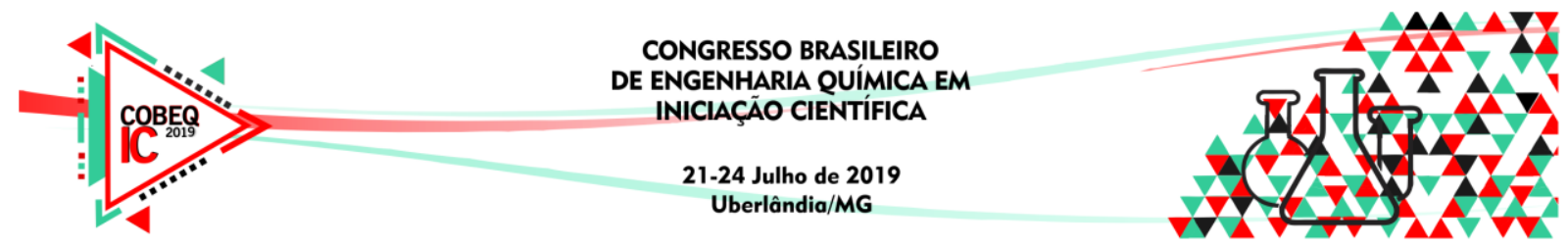

\section{CONCLUSÃO}

Os resultados obtidos são para àquelas condições de clima no dia do experimento e que são variáveis ao longo do dia. A secagem do cubiu a partir do secador de exposição à radiação solar direta na região amazônica foi efetiva e satisfatória, na qual observou-se a diminuição da razão de umidade com o decorrer do tempo em poucas horas de operação. Devido às características da região, tropical de clima quente e úmido, pode haver variação significativa de temperatura, mas a tendência é que ela se mantenha num patamar elevado $\left(>30^{\circ} \mathrm{C}\right)$ e a configuração do coletar facilita a concentração de energia, o que tende a facilitar a secagem. Portanto, precisa-se ainda avaliar a secagem em diferentes condições climáticas para se ter uma melhor compreensão de como o clima local influencia no processo. As fatias sofreram escurecimento ao longo do tempo de secagem, o que sugere a necessidade de realização de um pré-tratamento para evitar a oxidação do fruto.

\section{REFERÊNCIAS}

CHAUHAN, P. S.; KUMAR, A.; TEKASABUL, P. Applications of software in solar drying systems: a review. Renewable and sustainable energy reviews, 51, p 1326-1333, 2015.

RODRIGEZ, A.; BRUNO, E.; PAOLA, C.; CAMPANONE, L; MASCHERONE, R. H. Experimental study of dehydration processes of raspberries (Rubus Idaeus) with microwave and solar drying. Food Science and Technology, Campinas, Ahead of Print, ISSN 0101-2061, 2018.

SERENO,A. B; GIBBERT, L; BERTIN, R. L; KRUGER, C.C. Cultivo do Mana-Cubiu (Solanum sessiliforum Dunal) no litoral do Paraná e sua contextualização com a segurança alimentar e nutricional. Divers@ Revista Eletrônica Interdisciplinar, v.10, n.2, p.123-132, jul./dez 2017.

SILVA, D. F.P.; ROCHA, R. H.C.; SALOMÃO,L. C. Postharvest quality of cocona (Solanum sessiliforum Dunal) stored under ambient conditions. Rev. Ceres, Viçosa, v.58, n.4, p.476-480, jul/ago, 2011.

SILVA FILHO, D. F.; ANUNCIAÇÃO, FILHO, C.; NODA, H.; REIS, O. V. J. Análise Multivariada da Divergência Genética em 29 populações de Cubiu (Solanum sessiliforum Dunal) avaliada na zona da mata do estado de Pernambuco. ACTA AMAZONICA 25(3/4), p. 171-180, 1995.

SILVA, E. S.; OLIVEIRA, J.; MACHADO, A. V.; COSTA, R. O. Secagem de Grãos e Frutas: Revisão Bibliográfica. Revista Brasileira de Agrotecnologia (Garanhuns - PE - Brasil), v. 5, n.1, p. 19-23, jan-dez, 2015.

YUYAMA, L. K. O.; PEREIRA, Z. R. S.; AGUIAR, J. P. L.; SILVA FILHO, D. F.; SOUZA, R. F. S.; TEIXEIRA, A. P. Estudo de influência do Cubiu (Solanum sessiliforum Dunal) sobre a concentração sérica de glicose. Rev Inst Adolfo Lutz, 64(2), p.232-236, 2005.

YUYAMA, L. K. O.; MACEDO, S. H. M.; AGUIAR, J. P. L.;FILHO, D. S.; YUYAMA, K.;FAVARO, D. H. T.; VASCONCELLOS, M. B. A.Quantificação de macro e micronutrientes em algumas etnovariedades de Cubiu (Solanum sessiliforum Dunal) ACTA AMAZONICA, vol 37(3), p 425-430, 2007. 